\title{
CONTRIBUIÇÃO A UMA ANÁLISE SÓCIOSSEMIÓTICA E DE PROCESSO CULTURAL: LÉXICO, METATERMOS, MODALIDADES \\ CONTRIBUTION A UNE ANALYSE SOCIO-SEMIOTIQUE DU PROCESSUS CULTUREL: LEXIQUE, MÉTATERMES, MODALITÉS.
}

\author{
Texto original em francês: Prof. Dr. Cidmar Teodoro Pais (in memoriam) \\ Universidade de São Paulo - USP
}

Tradução: Profa. Dra. Maria de Fátima B. de M. Batista Universidade Federal da Paraíba - UFPB

\begin{abstract}
RESUMO. Neste trabalho, o autor propõe metamodelos que permitem examinar certos aspectos do processo histórico das culturas, no quadro de uma abordagem sociossemiótica e de semiótica das culturas. A formalização, não relacionada às conotações específicas de determinada cultura, autoriza estudo contrastivo da axiologia de diferentes culturas, com a necessária fiabilidade. São estudadas as tensões dialéticas, os percursos dialéticos de produção e os ciclos que se realizam através dos termos complexos de microssistemas, como os de ordem, civilização, barbárie, produtividade científica e tecnológica, sistema de dominação, sistema produtivo, cidadania plena, tradição, modernidade, experiência e criatividade. Embora variem e se manifestem em graus diversos, segundo as diferentes culturas e sociedades, observa-se que aquelas tensões, percursos e ciclos descritos acham-se sempre presentes em seus processos históricos. Constituem, assim, critérios científicos válidos, para a elaboração de uma semiótica das culturas e de uma tipologia semiótica das culturas. Nessa perspectiva, o autor aplica esses modelos a algumas facetas da cultura e da sociedade brasileiras, para melhor analisar certos processos sociais, como os da ascensão, cooptação, discriminação social, marginalização, seja ao nível da sociedade como um todo, seja ao nível da estrutura de poder das instituições. Finalmente, o autor, baseando-se nesses metamodelos, examina as tensões e as relações de confronto que se estabelecem entre o discurso da política científica e tecnológica, o discurso científico, tecnológico e educacional, de um lado, e o discurso institucional da Universidade brasileira, de outro, de que decorrem aspirações e frustações. Trata-se de questões complexas; uma análise semiótica dessas relações - mais precisamente orientada para a sociossemiótica e a semiótica das culturas - , assim como uma análise léxico-semântica dos metatermos envolvidos parecem mais úteis, para uma melhor compreensão dos processos em causa.
\end{abstract}

\section{Preliminares}

Pretendemos apresentar, aqui, alguns metamodelos que temos desenvolvido e que permitem examinar certos aspectos do processo histórico das culturas, bem como microssistemas de valores, sustentados em discursos manifestados no seu interior, como parte de uma abordagem semântica, sóciosemântica e em semiótica das culturas. Para isso, retomamos e reformulamos reflexões feitas em um trabalho anterior ${ }^{1}$.

\footnotetext{
${ }^{1}$ PAIS, C.T - Pour une aproache sociosémiotique du processos culturel: lexique et métatermes. In :
} PAIS, C.T. Conditions sémantico-syntaxiques et sémiotiques de la productivité systemique, lexicale et 
Diferindo da semiótica filosófica e opondo-se à semiologia estruturalista, a semiótica científica, desenvolvida a partir de propostas Hjelmslevianas, caracteriza-se como ciência social, na fase pós- moderna, por uma ruptura epistemológica, pela ampliação do seu objeto, pela sua vocação multidisciplinar, pelo fato de considerar sistemas semióticos e seus discursos como processos de produção de significação, informação e ideologia, pela elaboração pesquisada de uma concepção dialética de sistema e estrutura, pelo uso de lógicas modais e dialéticas em sua metalinguagem de análise.

A sociossemiótica, ramo mais recente e um dos mais fecundos,[...] estuda os discursos sociais não literários, como, por exemplo, os discursos científicos, tecnológico, político, jornalístico, publicitário, pedagógico, burocrático, entre outros. Tais discursos são chamados não literários porque a função estética, embora possa estar presente, não é dominante, nem definidora de sua função social primeira e não determinante de sua produção, valorização e eficácia; são ditos sociais por que se caracterizam por um enunciado e um enunciatário necessariamente coletivos, um segmento da sociedade, ou até mesmo, a sociedade inteira, embora o emissor e o receptor sejam indivíduos do ponto de vista biológico. Eles se caracterizam, ainda, por estruturas de poder específicas, sustentando-se em tensões dialéticas e percursos dialéticos de produção próprios, pelas relações intersubjetivas e espaço-temporais de enunciação e enunciado, assim como por mecanismo de argumentação, veridicção, persuasão, interpretação, manipulação/contra manipulação/sedução, igualmente específicos, suscetíveis de definir normas discursivas práticas e transfrásticas, enquanto conjunto de constantes e coerções que constituem, portanto, os universos de discurso. Eles apresentam diferentes níveis de ideologia subjacentes, de estrutura semântica profunda rica e claramente determinada, em que se pode detectar uma ideologia completa, estritamente relacionada, tanto a seu modo de existência e de produção, como a seu estatuto sociossemiótico e a uma estrutura hiperprofunda de conceptualização particularmente árdua².

discoursive. These de Doctorat d'Etat. Paris, Lille, Université de Paris-Sorbonne, Atelier National de Reproduction des Theses, 1993, p. 603-640

2 Para o conjunto de essas considerações ver cf Pais, C. T. Aspecto de uma tipologia dos universos de discurso Op cit, p. $43-65$. 
O estudo destes múltiplos aspectos conduz à obtenção de um poderoso método de análise do discurso, a uma melhor explicação da dinâmica dos universos dos discursos, a parâmetros mais religiosos para uma tipologia complexa dos discursos, assim como, com a ajuda do conceito de macrossemiótica ${ }^{3}$, traz para análise, sob um novo ângulo, os processos semióticos e a semiótica da cultura, entendida em seu sentido antropológico, que oferece novos critérios para uma tipologia das culturas. Uma melhor compreensão do dinamismo das culturas se revela útil para a formulação de políticas de desenvolvimento social eficazes.

Com efeito, consideremos que a macrossemiótica, como vimos anteriormente, é o conjunto das semióticas-objeto, isto é, dos sistemas de significação e de seus discursos em operação numa mesma comunidade linguística e sociocultural ou, em outras palavras, o conjunto dos processos semióticos de uma dada cultura. É possível, no processo de produção dos recortes culturais, no nível das estruturas hiperprofundas que os diferentes sistemas semióticos e seus discursos, pertencentes a uma mesma macrossemiótica, produzem recortes culturais coerentes e compatíveis, sustentem uma visão de mundo igualmente coerente, uma ideologia subjacente a esta cultura e a seus discursos ${ }^{4}$ cuja análise fornece elementos importantes para tipologia das culturas já mencionada.

\section{Ordem, civilização e barbárie}

A título de exemplo das possibilidades de estudo, apresentamos, aqui, sumariamente, um modelo que elaboramos e formalizamos graças à utilização de modalidades complexas, inscritas nos eixos e percursos dialéticos da semântica profunda, característicos das estruturas de poder. Este modelo, em nosso entender, deve ser tomado como uma proposta primária e provisória. Inspiramonos na história escrita e na reconstrução possível dos períodos não documentados, sem entrar na discussão infindável de sua veracidade, examinando seu conjunto como um macrotexto ${ }^{5}$.

\footnotetext{
${ }^{3}$ Cf., por exemplo, PAIS, C. T. - Elementos para uma tipologia dos sistemas semióticos; Op. Cit., p. 4460

${ }^{4}$ Cf., POTTIER. B. - Linguistique générale. Op. Cit., p.7-23, 44-48, 59-83; cf. também, por exemplo, PAIS, C. T. Conditions sémiotiques et semântico-syntaxiques de la productivité lexicale et discursive.

5 Cf., por exemplo, VARIORUM - Histoire générale des civilisations. (Publicada sob a direção de Maurice Crouzet, 7 vol. Paris, Puf, 1965.
} 
Uma abordagem sociossemiótica preliminar do processo histórico da cultura, que apresentamos num congresso internacional ${ }^{6}$ tratava de suas grandes etapas: ordem, civilização e barbárie. Foi reformulada em dois trabalhos subsequentes $^{7}$ e deve, em seguida, ser retomada, modificada e melhorada. Nós a retomamos, de forma resumida, como a primeira de uma série de modelos que discutiremos aqui. Parece-nos indispensáveis recordar, em seguida, que eles constituem metamodelos (e não modelos descritivos) no sentido epistemológico e que, por esta mesma razão, os lexemas selecionados são os metatermos e tem um significado especializado (abstração) que não corresponde sempre a seu "sentido comum".

Servimo-nos, aqui, como ponto de partida para a elaboração do modelo, do binômio autoridade/liberdade, da forma como se tornou operacional no processo histórico da civilização, herdeira dos valores greco-romanos e da concepção humanística.

Autoridade e liberdade são os termos contrários - considerados como metatermos - e, como tais, coexistem, obrigatoriamente, configurando duas tendências contrárias e gerando uma tensão dialética, epicentro do processo e lugar do conflito produtivo. O lexema autoridade se define por uma combinatória de modalidades complexas poder-fazer-querer ; poder-fazer-dever; não-poder-fazerfazer. Trata-se, pois, da autoridade legítima, sempre delegada pela sociedade, enquanto Destinador daquela, sempre limitada e para fins específicos. Por esta mesma razão, ela detém o poder de persuasão, não o de manipulação e a imposição absoluta e irrevogável não lhe vem face ao equilíbrio dinâmico que a sustenta em sua articulação com a liberdade e que, se rompida, a desfigura, 0 lexema liberdade se define, por conseguinte, pelas modalidades complexas poder-não-querer; podernão-dever; poder-não-fazer. Tem como destinador, também, a sociedade e, como destinatário o indivíduo-sujeito e ou o grupo, o segmento social- sujeito.

\footnotetext{
${ }^{6}$ Cf. PAIS, C.T. Para uma abordagem sociossemiótica do processo histórico da cultura; ordem, civilização e barbárie. In: Anais do Segundo Congresso Internacional Latino-Americano de Semiótica. 1987, Rosário, Associação Argentina de Semiótica.

${ }^{7}$ Cf. PAIS, C.T.. Sociossemiótica e semiótica da cultura in: Anais do IV encontro Nacional da ANPOLL Recife, ANPOLL, 1989, p.795-800, IDEM - Sociossemiótica, semiótica da cultura e processo histórico: liberdade, civilização e desenvolvimento in: Anais do $V$ Encontro Nacional da ANPOLL. Porto Alegre, ANPOLL, 1991, p.452-461.
} 
O termo contraditório de autoridade é força, muitas vezes chamado autoritarismo, quando diz respeito às relações humanas, ou, de maneira mais ampla, quando é compreendido como autoridade auto-delegada (ou seja, quando o sujeito é autodestinador) e não limitada. Define-se pela combinação das modalidades complexas não-poder-fazer-querer; não-poder-fazer-dever; poderfazer-fazer. Aqui a autoridade não detém o poder de persuasão, mas o de manipulação, sendo seu atributo o poder de imposição absoluto e irrevogável. 0 termo contraditório de liberdade é o lexema disciplina caracterizada, enquanto competência adquirida e reguladora da competência, como autodestinada $(0$ destinador é o próprio sujeito), definida pelas modalidades complexas: nãopoder-não-querer, não-poder-não-dever, não-poder-não-fazer.

Temos, assim, constituído um quadro axiológico que permitiria nele inscrever os diferentes processos de produção discursiva e sua articulação com as práticas sociais. Nessas condições, o processo histórico da cultura se desenvolveria em grandes etapas que, na sucessão dos ciclos realizados como percursos dialéticos, configuraria, na realidade, um continuum, num percurso através dos termos complexos autorizados por esta axiologia.

Se aceitamos que o octógono semiótico constrói, deste modo, o processo histórico da cultura, a posição correspondente do termo neutro será a da nãocultura, a da natureza, definida pela combinação dos termos força - disciplina que preside as relações da banda de lobos, da manada e da horda humana no nível, talvez, do homo faber. O grau de liberdade é praticamente nulo, assim, compreendido pelo chefe do grupo, igualmente submisso aos impulsos e as determinações biológicas.

A segunda grande etapa do processo da cultura é caracterizada pelo termo complexo ordem, definido pela combinação autoridade - disciplina, de forma similar - a situação que observamos, ainda hoje, nas sociedades extremamente homogêneas. Nesta última, a especialização do trabalho é mínima, as práticas comuns aos integrantes do grupo e a diversidade discursiva são reduzidas. De um modo geral, coexistem, inicialmente, dois universos de discurso, o coloquial, da comunicação quotidiana e utilitária e o sagrado ou ritual que assume, simultaneamente, as funções de discurso teológico, filosófico, cientifico tecnológico e jurídico que explicam o homem e o mundo, estabelecendo a ordem 
social, controlando e sancionando as práticas. O saber é, em grande parte, patrimônio comum, as atividades, condivididas, o grau de liberdade, bastante reduzido, destacando-se, nesse universo, as figuras do chefe do poder político e o do feiticeiro ou sacerdote, o depositário privilegiado do saber, eles próprios, às vezes, prisioneiros e servidores da tradição recebida dos pais. São exemplos típicos do estado de ordem as sociedades indígenas, os primeiros tempos da republica romana, a organização interna do sistema feudal na alta Idade Média, entre outros.

Entretanto, o desenvolvimento científico e tecnológico, em um sentido mais amplo, o aumento das atividades econômicas, a progressiva diversificação e especialização do trabalho se traduzem pela constituição de sociedades cada vez mais heterogêneas e pela aspiração a graus sempre maiores de liberdade, fenômeno já observável, por exemplo, na Antiguidade, em Antenas, durante os séculos quinto e quarto A.C, ou no apogeu da republica romana e, ainda, durante a renascença, na retomada dos valores gregos - romanos e na concepção antropocêntrica do mundo, no humanismo, acentuando-se, também, nas sociedades altamente heterogêneas, industriais e pós - industriais. Chegou-se, assim, no curso destes períodos, como de inúmeros outros, ao estado que chamamos civilização, lexema e termo complexo que, em nosso modelo, se define pela combinação autoridade/liberdade. São características dos estados ditos civilizatórios pelo mais alto grau de liberdade destinada, pela sociedade, aos sujeitos, somente limitada pela autoridade que a assegura, justamente, uma diversidade e complementaridade das práticas, a constituição de um número considerável de grupos e/ou seguimentos sociais que se mantêm e se afirmam através do universo de discursos próprios, dai seu numero e sua diversidade. A estes, impõem - se, então, questões cruciais como aquelas dos mecanismos e dos critérios determinantes da valorização e da eficácia dos discursos.

Ao estado dito natureza, o destino dos indivíduos está determinado pelas forças de coerção que regem a horda, o grau de liberdade praticamente nulo e parece mesmo estranho falar de sujeitos. No estado dito de ordem, existe certa diversidade de destinos, um grau de liberdade reduzida, no interior dos caminhos, a consciência da possibilidade de vitória ou perda, as opções são raras e constantes, seu dito civilização, o grau de liberdade destinado pela sociedade, aos indivíduos é muito maior, sendo dada a diversidade dos seguimentos, dos 
universos de discursos e das práticas, os algarismos mais numerosos, a repetição e a reiteração cedem espaço a criatividade e as opções; o indivíduo - sujeito pode, numa proporção maior, ser o mestre de seu destino; a liberdade limitada, unicamente, pela autoridade delegada, destinada pela sociedade - destinador, na medida em que ela é necessária para assegurar a própria liberdade.

Uma vez atingido este estágio, entretanto, chega-se, numerosas vezes, ao longo da história, a um período caracterizado pela exacerbação da liberdade individual, em prejuízo do equilíbrio e do bem - estar social, simultaneamente à conquista, por certos seguimentos, de uma autoridade não delegada e não limitada, sendo estas tendências dirigidas a praticas sociais diferentes como, de um lado, a exacerbação do direito de propriedade, de gozo ou de consumo e, de outro, graves limitações de liberdade política. Os destinos dos indivíduos tornam-se, progressivamente, aleatórios, o tecido social se rompe, a identidade cultural se fragmenta. Temos, então, a barbárie, definida pela combinatória liberdade - força.

O conjunto das relações, da tensão, dos percursos e processos de transformação pode ser formalizado como a seguir:

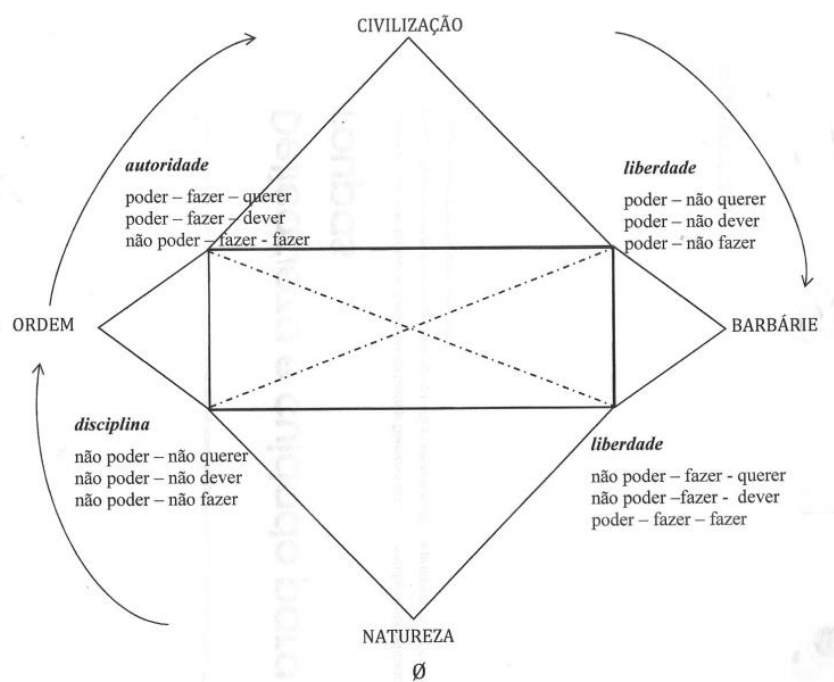

FIG. 1 - Ordem, civilização, barbárie

Do ponto de vista complementar, a sucessão dos ciclos que caracteriza o desenvolvimento do processo histórico da cultura, entendida como um contínuum, pode ser ,de forma sucinta, assim formalizada: 


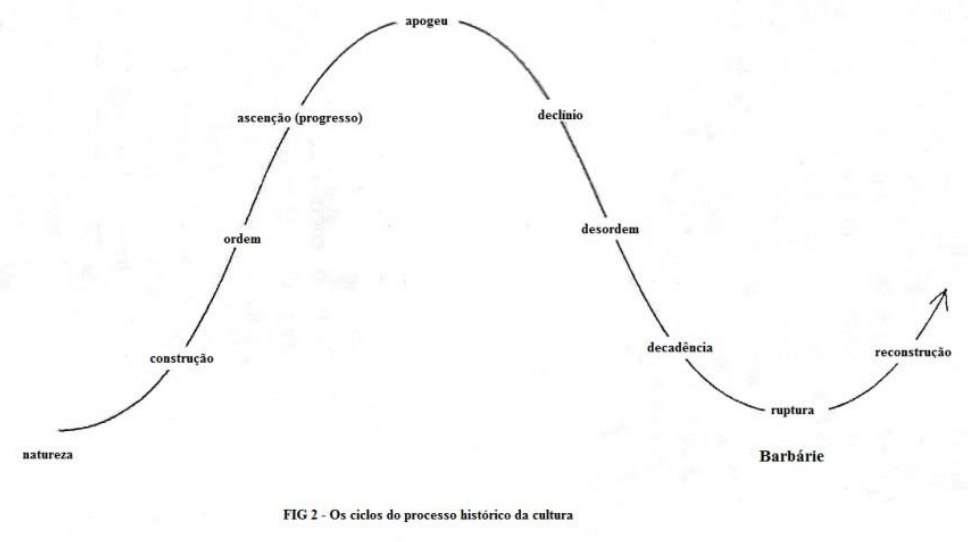

FIG 2 - Os ciclos do processo histórico da cultura

Nos estados de civilização e barbárie de sociedades heterogêneas, diferentes segmentos sociais podem se situar em posições diversas, seja nos termos simples, seja nos complexos, seja, ainda, em nos diversos graus dos percursos dialéticos possíveis, sobre os eixos dos contrários e dos contraditórios. Por exemplo, numa dada sociedade, uma ordem religiosa ou uma hierarquia militar podem se manter na ordem, em sua organização interna (autoridade disciplinar) ao mesmo tempo em que grupos de delinquentes se fixam na barbárie (liberdade - força), que certos partidos políticos tendem a organizar, manter-se ou reconstituir o Estado de direito (autoridade - liberdade), que outros segmentos se distribuam em pontos distintos dos percursos entre estes termos.

Entretanto, uma vez atingido o estado de barbárie, o progresso técnico científico e as atividades econômicas afetaram, fortemente, o equilíbrio ecológico que torna indesejável, para muitos, o retorno ao estado de natureza e, de alguma forma, irrealizável. Duas possibilidades se apresentam: Na primeira a civilização, que se dissolveu no estado de barbárie, permanece em impasse até sua destruição, processo do qual existem exemplos na história. Na segunda, da qual, igualmente, existem numerosos exemplos, retoma-se a construção da civilização através do penoso caminho da ordem, até que seja possível reconquistar o equilíbrio social em termos de autoridade - liberdade, em outras palavras, aquilo que se costuma chamar, na civilização ocidental, a democracia.

\section{A construção do saber e a produção tecnológica}


Por outro lado, é um fato, pertinentemente, conhecido e reconhecido que o homem, espécie única tanto quanto ser biológico, não se tornou, verdadeiramente, homem, a não ser quando desenvolveu as linguagens, verbais e não-verbais-homo semioticus--- das culturas e sociedades diferentemente estruturadas, dito com outras palavras, quando ele se tornou um animal cultural, social e histórico. A diversidade linguística, semiótica, cultural e social é o apanágio do homo sapiens. Só se conhece, portanto, uma cultura que tenha desenvolvido um saber - um processo de acumulação e transformação do conhecimento, evidentemente, em graus e rapidez variáveis e uma aplicação a práticas, ou seja, a uma tecnologia. É indispensável, aqui, não se deixar enganar pela conotação moderna de tais termos. Assim, por exemplo, um saber existe, desde que se conhece o movimento dos astros do firmamento, sejam eles observados a olho nu ou graças aos meios da astronomia atual, da mesma forma, uma tecnologia existe, desde a fabricação e o emprego de uma lança ou de um arco e de flechas, até a produção e o lançamento de um míssil balístico, do fogo de madeira, ao fogo de micro - ondas, do cuidado pelas ervas aos antibióticos, da cabana ao imóvel, do emprego de um tronco de árvore, da canoa ao navio com propulsão nuclear, do tambor às telecomunicações via satélite e assim por diante. De certa maneira, cultura (recortes culturais, sistemas de valores, visão de mundo), ciência em sentido lato (produção, acumulação e transformação do saber), ciência aplicada e ou tecnologia em sentido lato (aplicação de um saber a um fazer) são indissociáveis em todas as sociedades humanas; ciência e tecnologia, no seu sentido próprio, são processos de produção, inseridos no processo maior que é aquele do processo histórico da cultura.

Por estas razões, quando discutimos, num trabalho anterior, os aspectos relativos à politica científica e tecnológica, nós elaboramos outro metamodelo que se insere no modelo geral do processo histórico da cultura, resumido acima e que, em nosso entender, devemos retomar, sumariamente, neste novo contexto de reflexões. A ciência lato sensu, certamente, é um processo cultural, uma prática social, o processo de pesquisa da verdade e construção do saber, para a melhoraria das condições de vida do homem, pesquisa interminável e permanente reconstrução que pode se designar pelos metatermos geral - o conhecimento definido pela combinatória de modalidades poder-fazer-saber, a aplicação de um saber a um fazer, chamada ciência aplicada e/ou tecnologia lato sensu, pode ser 
designada, por seu turno, pelo metatermo geral competência e se define pela modalidade complexa poder-saber-fazer. Como termos contrários, coexistem, necessariamente, e se sustêm em uma tensão dialética, num processo de alimentação/ realimentação 0 termo contraditório de ciência é, evidentemente, ignorância, definida pela modalidade complexa não-poder-fazer -saber; assim, o termo contraditório de competência é, evidentemente, incompetência, definida, por sua vez, por não-poder -saber-fazer. Estabelece-se, então, um percurso dialético de produção entre ciência e competência; a partir de um saber (conhecimento), é possível aplicar a um fazer; esta instancia constitui o lugar de validação/invalidação do saber, na medida em que ai se verifica um poder de explicação do modelo - até o ponto em que sua aplicação é satisfatória - e seus limites - além dos quais sua aplicação é insatisfatória, fatos que o modelo não explica que criam uma situação de ignorância. Esta, por seu termo, remete os novos modelos ao processo de pesquisa da verdade e (re)construção do saber. Nestas condições, ciência e competência não são produtivas a não ser quando articuladas na relação de alimentação/realimentação e inseridas, como consequência, no percurso dialético citado acima.

Uma das características constantes dos países em via de desenvolvimento e, infelizmente, a opção pela formula de desenvolvimento defendida, fundada sobre a importação de tecnologia (caixas negras) com a consequente discriminação e asfixia da pesquisa fundamental, ou seja, o divorcio entre pesquisa fundamental e ciência aplicada e/ou tecnologia, da qual resulta uma progressiva dependência tecnológica e econômica, uma dívida externa, uma dívida interna, uma dívida social irrecuperável, a esterilização da universidade e das instituições da pesquisa, a ausência de comunicação entre universidade e sociedade. Em todas as sociedades, entretanto, esta anomalidade aparece em um grau maior ou menor, ou de forma generalizada ou localizada em segmentos. Chega-se ao fato de que os termos "simples" - ciência, competência, incompetência e ignorância - se combinam em termos complexos. A combinação ciência X competência estabelece o epicentro do processo de produção definido como produtividade com responsabilidade social está, seguramente, segundo o sistema de valores da cultura em questão; a combinatória ciência $X$ incompetência configura o termo complexo teoria inoperante (poder-fazer-saber mais não poder-saber-fazer) a combinatória 
competência X ignorância determina o termo prática irresponsável (poder-saberfazer mais não poder-fazer-saber) ou criminal, enfim, a combinatória incompetência/ignorância define o termo neutro do octógono semiótico: a nulidade. Esquematicamente, temos:

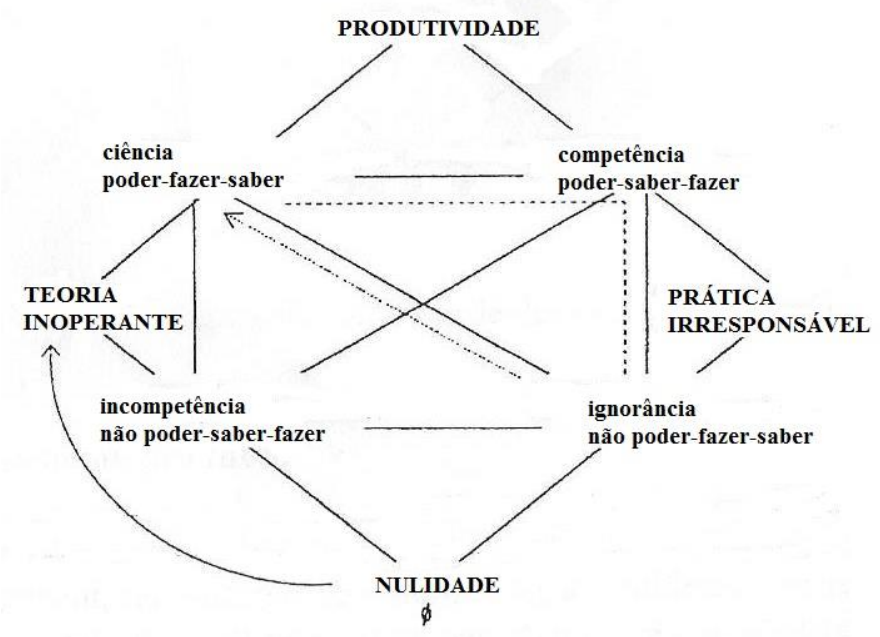

\section{FIG. 3 CIÊNCIA x COMPETÊNICA}

\section{As relações de dominação}

É um fato bem conhecido que, em todas as épocas da história, o saber/conhecimento e a competência conferem o poder. Este poder pode ser utilizado, segundo diferentes orientações políticas, em todas as direções, como instrumento de dominação ou de liberação. Compreende-se, aqui, claramente, que a política científica e tecnológica lato sensu, sob as diversas formas em que se apresenta, nas várias sociedades, está indissociavelmente ligada ao sistema de valores da cultura em questão e à orientação política do estado ou dos seguimentos que o contestam, internos ou externos, em cada caso. De qualquer maneira, todas as sociedades têm um sistema de dominação, estabelecido após o modelo de organização social, imposto ou livremente escolhido, segundo o primeiro modelo descrito neste trabalho. Parece lícito, portanto, propor um terceiro metamodelo, apresentado, aqui, suscintamente, um modelo didático, por assim dizer, do sistema de dominação e de sua transformação e/ou ruptura, pelos fatores relacionados à sua dinâmica intrínseca, pelas interferências exteriores à sociedade, a sua combinação. 
Todo sistema de dominação se sustenta na tensão dialética dominante/dominado; o termo contraditório de dominante é não dominante, o termo contraditório de dominado, não dominado. 0 percurso dialético da mudança social pela transformação lenta, pela ruptura (revolução, por exemplo) define-se, assim, no qual o dominado rompe a dominação, passa a anão dominado e, assim, a dominante, enquanto que, o ex-dominante passa a dominado (por execução, expropriação de bens, exilio ou simples readaptação.). Deste processo, existem inumeráveis exemplos na História, o movimento dos irmãos Gracos, na republica romana, o Renascimento, a Revolução Industrial, a Revolução Francesa, a Revolução Russa, entre outros. A combinação dominante $X$ não dominado define o termo complexo concernente ao grupo dominante, chamado, nos diferentes casos, aristocracia, burguesia, casta superior, etc e que poderemos, talvez, designar, no modelo, pelo metatermos elite; a combinação dominado $\mathrm{X}$ dominante define $\mathrm{O}$ segundo termo complexo, o grupo, a classe, a casta, o segmento daqueles que trabalham, os trabalhadores; a combinação não dominado X não-dominante define o termo neutro, a marginalidade social. Temos assim:

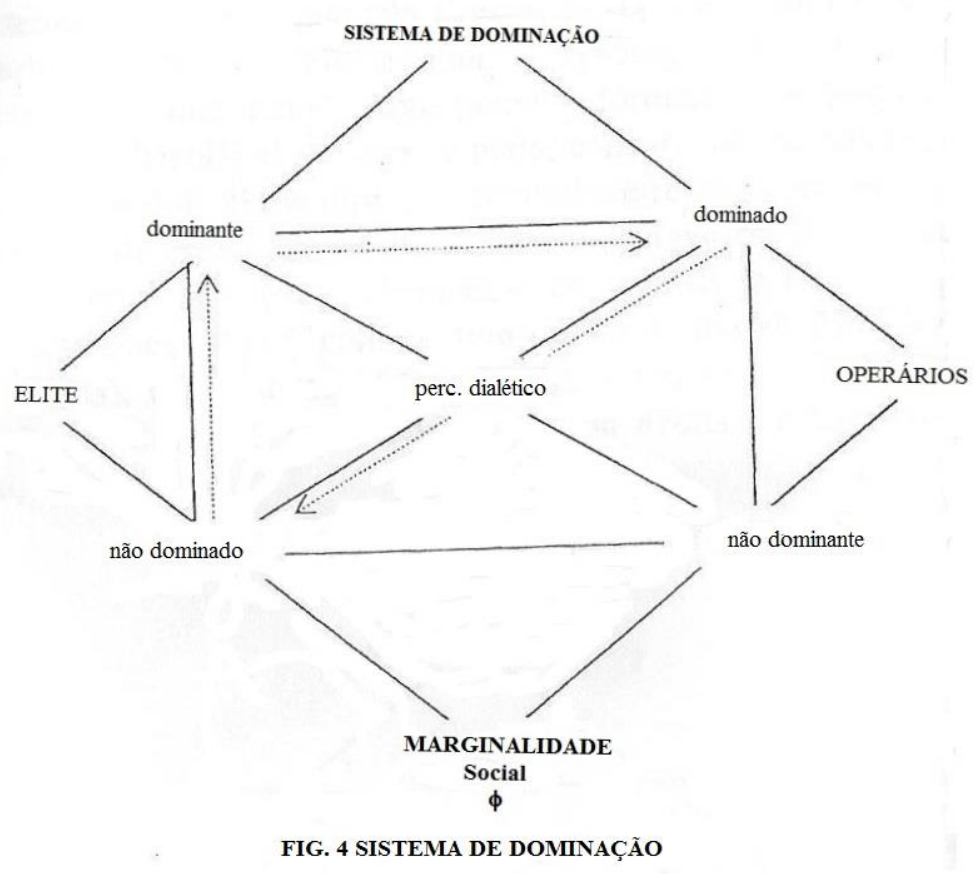

FIG. 4 - SISTEMA DE DOMINAÇÃo

\section{0 sistema produtivo}


Nas sociedades homogêneas, ditas primitivas, embora exista, evidentemente, um sistema de dominação, o problema das relações entre capital e trabalho não se impõe. À medida que se acumula o conhecimento, a competência aumenta, estabelece-se uma progressiva especialização e divisão do trabalho, paralelamente à detenção, por um ou vários grupos, de meios de produção, da propriedade, da tecnologia, do poder de tomar decisão. A separação capital/trabalho torna-se, sempre, mais explicita, nas sociedades heterogêneas, sobretudo, as industriais e pós - industriais. Desta forma, o sistema produtivo se mantém na tensão dialética capital/trabalho. 0 termo contraditório de capital é não - capital; o termo contraditório de trabalho, não - trabalho; dai resultam os termos complexos: elite (capital X não - trabalho), mão de obra (trabalho X não capital), e o termo neutro marginalidade econômica, que define indivíduos ou segmentos que não se encontram inseridos no sistema produtivo. Esquematicamente temos:

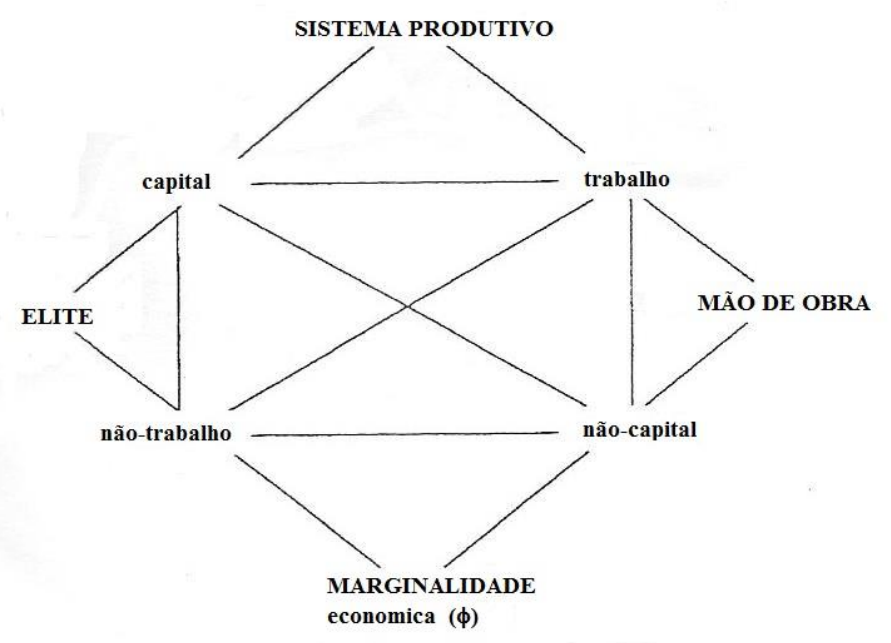

FIG. 5 - SISTEMA PRODUTIVO

\section{Os direitos dos cidadãos}

Os quatros metamodelos apresentados até aqui o foram, de forma sumária, pela limitação de espaço e porque alguns exigem um tratamento mais substancial. Todavia, acreditamos que, tomados em conjunto, eles nos conduzirão a reflexões sobre dois grandes temas, discutidos com tais nomes ou com outros em diferentes civilizações e culturas: a questão da cidadania e o conflito permanente entre tradição e modernidade. 
No primeiro caso, o Estado de Direito, a democracia como nós a vimos, define o equilíbrio dinâmico e a tensão entre liberdade e autoridade delegada, encarregada de assegurar a liberdade. Desta maneira, a distribuição diferente dos direitos e deveres está diretamente ligada aos estados de ordem, da civilização e da barbaria e oferece um critério para a tipologia das culturas e das sociedades. Em termos atuais, podemos formalizar um quinto modelo: Direitos e deveres se mantêm como contrários numa tensão dialética: o contraditório de direitos é não direitos; o contraditório de deveres é não - deveres. Dai resultam os quatro termos complexos designados; é útil chamá-los pelos metatermos elite (direitos $\mathrm{X}$ não deveres), massa (deveres X não direitos), cidadania plena (direitos X deveres), marginalidade social X política (não deveres X não direitos). Esquematicamente temos:

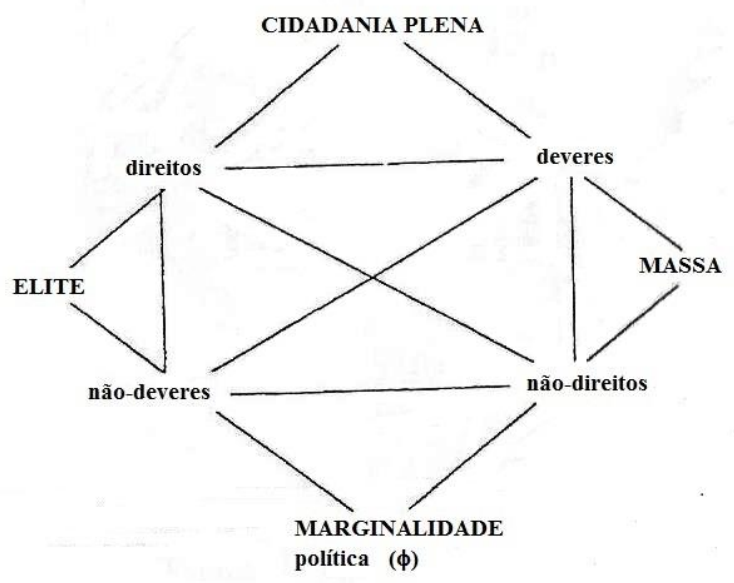

FIG. 6 - CIDADANIA

\section{Tradição e modernidade}

É importante observar que, nas sociedades heterogêneas, existem segmentos, de grupos ou de indivíduos, distribuídos pelos quatro cantos e definidos pelos termos complexos.

Inevitavelmente, tais reflexões nos conduzem a um tema ( ou problema) discutido ao longo da História, no antigo Egito, em Atenas, em Alexandria, em Roma - verdadeira obsessão dos romanos - na Renascença, nos séculos XVII e XIX, entre outros períodos, e que persiste, caracterizando-se, como sendo de estrema atualidade no mundo contemporâneo que é o do conflito e do equilíbrio dinâmico 
entre tradição e modernidade. 0 metatermo modernidade se define pela combinatória de modalidades complexas: querer-fazer-avançar, poder-fazeravançar, saber-fazer-avançar; seu contrário, a tradição se define como quererfazer-conservar, poder-fazer-conservar, saber-fazer-conservar; seus respectivos contraditórios são não-modernidade (não-querer-fazer-avançar, não-poder-fazeravançar e não-saber-fazer-avançar ) e não tradição (não-querer-fazer-conservar, não-poder-fazer-conservar e não-saber-fazer-conservar ). Se aceitarmos que a consciência histórica é uma das condições do desenvolvimento científico e técnico, econômico e social, da construção de sociedades mais livres, justas e democráticas, teremos que a tensão dialética modernidade/tradição é sustentáculo do termo complexo, qualificador das sociedades (ou instituições no seio delas) dinâmicas, nas quais, o progresso se entende como liberdade, civilização e desenvolvimento, inseridos no processo histórico. A combinatória tradição x não-modernidade define, por seu turno, o termo complexo, em que se enquadram as sociedades arcaicas. A combinatória modernidade X não tradição (sem consciência histórica) estabelece o termo complexo, em que se situam as sociedades em desenvolvimento perverso. Enfim, a combinatória não-tradição X não-modernidade define o status da sociedade em processo de ruptura. Semanticamente, nossa vontade:

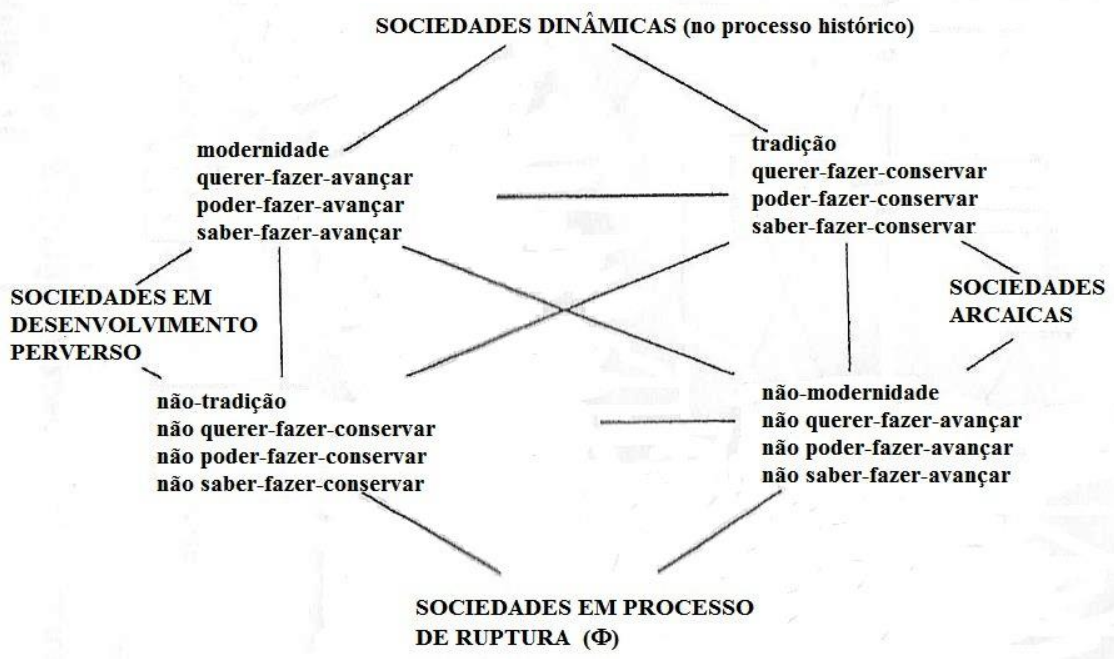

FIG. 7 - TRADIÇÃO E MODERNIDADE 
É apropriado assinalar, paralelamente, que, nas sociedades heterogêneas, sobretudo nas sociedades industriais e pós - industriais, como também, nas instituições que estão na universidade, por exemplo, existem grupos, setores, segmentos diferentes que se situam em posições distintas, identificadas pelos termos complexos ou em graus diversos, nos eixos dos contrários e contraditórios. Acontece o mesmo com as diferentes semióticas-objeto verbais, não-verbais e complexas, integrantes de uma cultura determinada, de modo que se observam grupos ou indivíduos inscritos na modernidade ou na tradição, quanto a suas roupas, quanto a seus ideais políticos e assim por diante.

\section{A maturidade}

Existem correlações entre a tensão tradição/modernidade e a tensão experiência/criatividade, bem como não se estabelece, jamais, a relação de dependência funcional. Nesses termos, a criatividade (querer/saber/poder-fazer o novo) e a experiência (querer/saber/poder-fazer o já conhecido) definem o termo complexo maturidade; experiência e não-criatividade, o termo complexo senilidade; criatividade X não experiência, adolescência; não-criatividade X não- experiência, o termo neutro, nulidade.

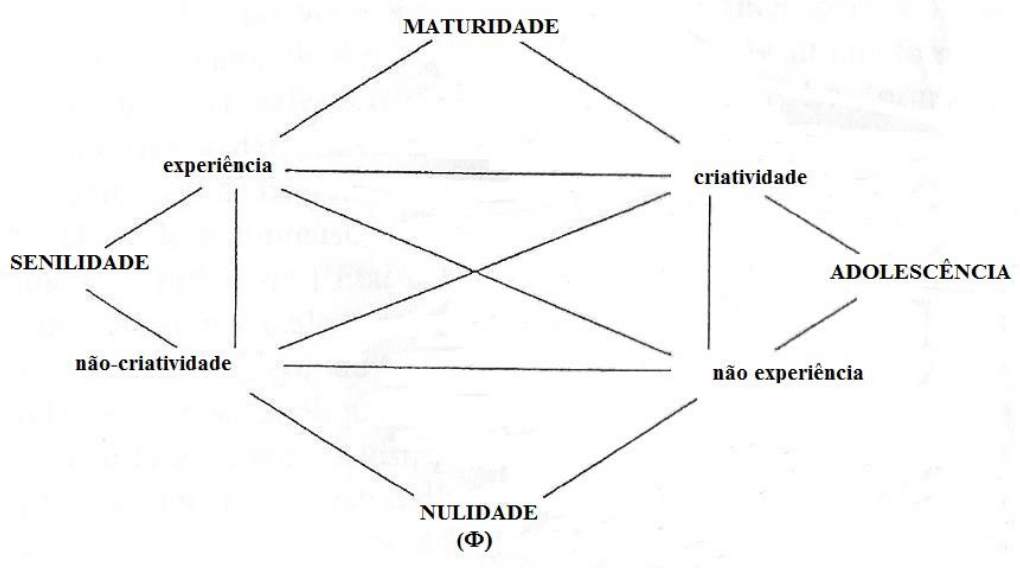

FIG. 8 - EXPERIÊNCIA E CRIATIVIDADE 


\section{Um ensaio analítico de alguns aspectos da semiótica da cultura brasileira.}

Nós procuramos construir metamodelos que permitem examinar certos aspectos do processo histórico da cultura, no quadro de uma abordagem sociossemiótica e em semiótica da cultura. Tentamos utilizar uma formalização mais adequada, ou seja, não ligada a conotações específicas de uma cultura dada, de maneira a autorizar um estudo contrastivo da axiologia de diferentes culturas dotado da confiabilidade necessária. Formulamos, então, octógonos semióticos, para estudar as tensões dialéticas, os percursos dialéticos de produção e o círculos que se realizam através de termos complexos de microssistemas como aqueles da ordem, civilização e barbárie (autoridade X liberdade), sistema de dominação (elite $\mathrm{X}$ trabalhadores), produtividade científica e técnica (ciência X competência), sistema produtivo (capital X trabalho), cidadania plena (direitos X deveres, Elite X massa), tradição e modernidade (processo histórico, dinamismo das sociedades, experiência X criatividade).

Embora os octógonos variem e se manifestem em graus diversos, ou se preferimos, devem ser destacados, segundo as diferentes culturas e sociedades, constatamos que as tensões, os percursos e os ciclos descritos e citados acima estão sempre presentes nos seus processos históricos. Eles constituem, portanto, em nosso entender, critérios científicos valorativos para elaboração de uma semiótica da cultura e de uma tipologia semiótica das culturas.

Nestas perspectivas, chegamos a aplicar estes modelos a algumas facetas da cultura e da sociedade brasileiras. Os modelos que propomos, a seguir, constituem construções teóricas realizadas a partir dos metamodelos precedentes.

\subsection{Processos de inserção e de discriminação sociais}

As relações de tensão e de confronto, de que falamos acima, podem ser melhor explicadas, em nossa opinião, se nos reportarmos aos princípios da organização social, sempre discutidos na historia do Ocidente e, mesmo fora daquela. Trata-se de duas propostas incompatíveis que já foram objeto de um debate na Antiguidade clássica, notadamente em Antenas. De um lado, temos o principio da igualdade formal que sustenta o sistema de valores da democracia e do Estado de Direito; por outro lado, temos o principio da superioridade natural que justifica a organização social à partir do governo estabelecido e conservado 
pelos excelentes(greco: apiõtoi; latim: optimi) que definem a aristocracia. Esta última concepção se manifesta, sob diferentes formas, como certo darwinismo social e suas variações, por exemplo, o poder segundo o mérito (meritocracia), a superioridade natural das leis do mercado etc, seguindo uma fórmula de evolução e seleção natural das espécies. 0 princípio aristocrático determina, na sua lógica interna, a marginalidade de homens e de nações.

Em numerosas sociedades modernas, viu-se o conflito entre uma concepção de Estado de Direito, sob o modo do parecer, e a organização social aristocrática, sob o modo do ser. Nós tentamos construir um modelo sumário destas relações, aplicando-as a alguns aspectos da cultura e da sociedade brasileiras. Assim, para evitar o perigo dos deslizamentos de sentido, quando se traduz de uma língua natural para outra, utilizamos, neste modelo, metatermos tomados de empréstimos ao português do Brasil.

Comecemos, portanto, pela oposição privilegio X restrição. 0 metatermo privilegio se define pelas modalidades complexas querer-fazer, crer-poder-fazer, crer-saber-fazer, crer-dever-fazer, enquanto que o metatermo restrição se define pelas modalidades querer-não-fazer, crer-não-poder-fazer e crer-não-saber-fazer $e$ crer-não-dever-fazer, inculcadas, objeto de um processo contínuo de introjeção. Assim, o metatermos não-restrição se caracteriza pelas modalidades não-quererfazer, não-crer-não-poder-fazer, não-crer-não-saber- fazer, não-crer-não-deverfazer, enquanto o metatermo não-privilegio se qualifica pelas modalidades nãoquerer-fazer, não-crer-poder-fazer, não- crer-saber-fazer, não-crer-dever-fazer. Não restrição e não privilegio constituem termos sub-contrários entre eles e termos contraditórios dos primeiros termos.

Desta maneira, a combinatória dos metatermos ditos simples determina os metatermos complexos: esperteza (articulação entre privilegio e restrição, em tensão dialética); a arrogância ( privilegio e não restrição); submissão ( restrição e não privilegio); ceticismo (não restrição e não privilegio). Assim, dois percursos se instauram entre os metatermos complexos: o percurso da inserção social, da arrogância à esperteza (ou, se se prefere, da ordem em direção barbárie). Ao formalizar essas relações com a ajuda de um octógono semiótico, temos: 


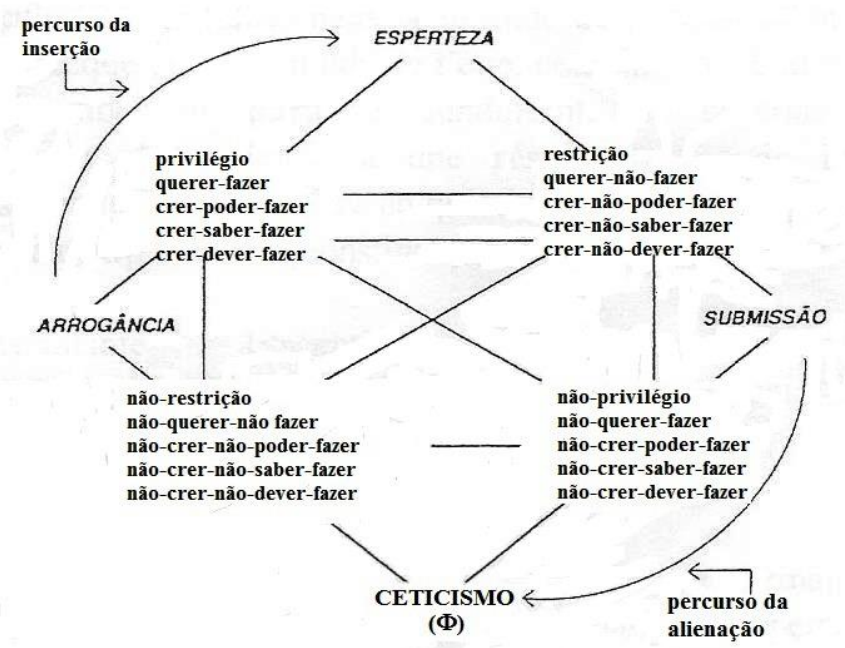

\section{FIG. 9 - PRIVILÉGIO E RESTRIÇÃO}

Nesses termos, parece-nos possível compreender melhor certos processos sociais como o da inserção social, da ascensão, da cooptação, da discriminação social, da marginalização, seja no nível da sociedade por inteiro, considerada como um todo, seja no nível da estrutura de poder das instituições. O octógono semiótico, assim construído, caracteriza a organização social aristocrática, sob o modo do ser. Ele decorre do complexo político e sociocultural descrito acima , igualmente da alternância das aspirações e frustrações, segundo as possibilidades de inserção, ou não, de indivíduos ou de grupos sociais. Uma tensão dialética é sustentada, então, entre dois termos contrários, ser - a lei do mais forte - e parecer - Estado de direito; seus contraditórios são, respectivamente, os termos nãoparecer - poder de fato - e não- ser - fraqueza, limitação. Podemos definir, em consequência, os metatermos complexos: sucesso (aspiração) = Lei do mais forte $\mathrm{X}$ poder de fato, fracasso (desencanto) = Estado de direito X fraqueza; identidade (inserção) $=$ Lei do mas forte (sob o modo do ser) X Estado de direito (sob o modo do parecer); marginalidade = poder de fato (sob o modo do não parecer) $\mathrm{X}$ fraqueza (sob o modo do não ser). A lógica interna do processo autoriza a inscrição de dois percursos: o percurso da cooptação (do sucesso-aspiração a identidadeinspiração) (o percurso da discriminação (do fracasso - desencanto) a marginalização - auto - expulsão.). Podemos, portanto, formalizar estas relações e percursos com a ajuda do octógono semiótico seguinte: 


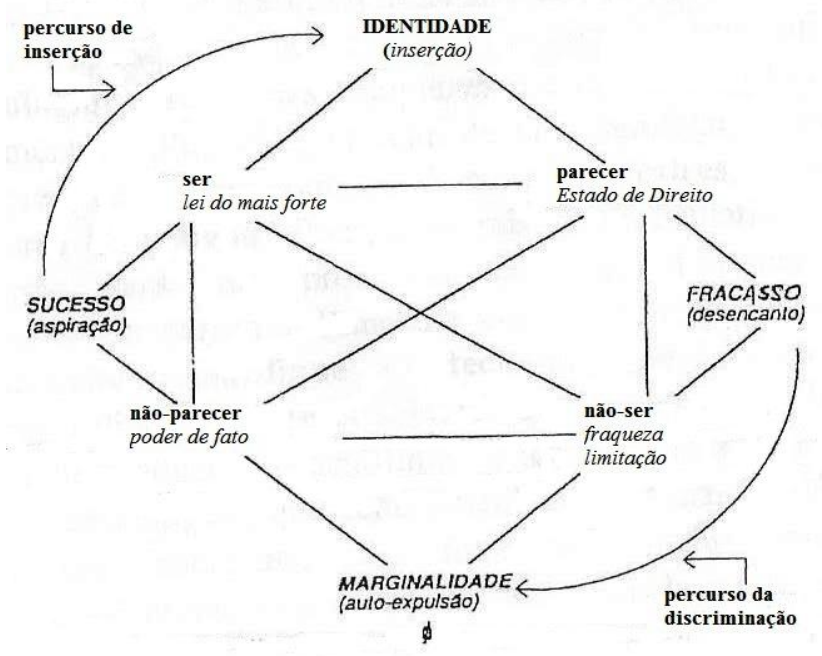

FIG. 10 - INSERÇÃO E DISCRIMINAÇÃO

Examinando os diversos metamodelos formulados, verifica-se uma correspondência coerente entre os termos neutros: nulidade no saber/saber fazer, marginalidade econômica, politica, social, marginalidade no processo histórico que, acreditamos, exige reflexões aprofundadas. Por outro lado, os processos assim considerados permitem, parecem, dar conta da combinatórica sememica dos metatermos ordem $\mathrm{X}$ barbárie, teoria inoperante $\mathrm{X}$ prática irresponsável, elite $\mathrm{X}$ trabalhadores, elite $\mathrm{X}$ mão de obra, elite $\mathrm{X}$ massa, desenvolvimento perverso $\mathrm{X}$ sociedade arcaica, privilégio $X$ restrição, aspiração $X$ desencanto.

Desta maneira, todos os processos sociopolíticos e socioculturais implicados na fórmula da organização social "aristocrática", sob o modo do ser, combinada com o Estado de Direito, sob o modo do parecer, conduzem pela combinatória semêmica dos valores, a um resultado - da análise sociossemiótica da cultura em questão - ou, se se prefere ao semema complexo, assim constituído pelos sememas parciais:

$<$ Resultante $_{\mathrm{Sc}}>=\{<$ ceticismo $>,<$ alienação política $>,<$ perto de identidade cultural $>$, < ruptura do tecido social $>\}$

Onde SC = semiótica da cultura.

Parece-nos possível, desta forma, formalizar as tensões e os percursos dialéticos intervenientes, as operações de transformação, os investimentos 
semânticos entre outros aspectos e obter, assim, uma melhor compreensão dos mecanismos de conservação e ruptura da axiologia e do tecido sociocultural.

\subsection{Dos discursos da politica científica, tecnológica e da educação ao discurso institucional da Universidade Brasileira: aspirações e frustrações}

Como vimos acima, o discurso científico na pesquisa fundamental considerado como processo de pesquisa da verdade e da (re)construção do saber, caracteriza-se pela estrutura do poder definida pela modalidade complexa, poderfazer-saber; os discursos da ciência aplicada e/ou tecnologia, enquanto aplicação de um saber a um fazer, define-se como um poder-saber-fazer. Parece-nos legítimo designá-los, respectivamente, pelos metatermos ciência (ou conhecimento) e competência. 0 termo contraditório de ciência é representado pelo lexema ignorância (não-poder-fazer-saber) e o de competência, pelo lexema incompetência (não-poder-saber-fazer).

Como assinalamos igualmente, acima, quando articulamos dialeticamente os termos simples, seus metatermos e os lexemas que os manifestam, é possível construir um octógono semiótico capaz de dá conta dessas relações nos discursos e práticas da ciência, da tecnologia e/ou ciência aplicada e da politica científica e tecnológica, em termos complexos. 0 discurso da pesquisa fundamental, de um lado e aquele da tecnologia ou ciência aplicada, de outro, são discursos contrários, juntos com suas estruturas de poder. Por esta razão, a articulação dos dois discursos, no processo constante de alimentação e realimentação constitui uma das condições sine qua non da produtividade cientifica e tecnológica, fundamentada sobre a responsabilidade politica e social. Constata-se, nos grandes centros de produção cientifica e tecnológica, nos países ditos subdesenvolvidos, que esta articulação é mantida, a custo de pesados investimentos, para fazer face, inclusivamente, à concorrência internacional. Ao contrário, na maioria dos países dito "em via de desenvolvimento", escolheu-se, frequentemente, uma politica científica e tecnológica perversa, caracterizada pela importação da tecnologia "para queimar as etapas do desenvolvimento" - acompanhada da descriminação da pesquisa fundamental local, daí uma crescente dependência tecnológica e econômica seguida das consequências sociais que se conhecem.

Gostaríamos de fazer uma breve análise da situação da universidade brasileira face a estes problemas. Com efeito, uma vez estabelecido o divórcio 
entre ciência e competência, uma cisão se verifica entre diferentes domínio do conhecimento, entre instituições e segmentos de instituições ditas de ensino e de pesquisa. Por outro lado, estes segmentos começam a funcionar, segundo o caso, seguindo outras combinações possíveis de metatermos; assim, a combinação ciência X competência (poder-saber-saber e não-poder-saber-fazer) conduz ao termo complexo da teoria inoperante; a combinatória competência $X$ ignorância (poder-saber-fazer X não-poder-saber-fazer) conduz ao termo complexo da prática irresponsável. Esses dois metatermos complexos se situam, em geral, no nível dos departamentos, (das unidades de formação e pesquisa) da Universidade; destas combinações perversas, decorre, ainda, outra que corresponde ao quarto termo complexo, a combinação incompetência X ignorância (não poder-saber-fazer X nãopoder-fazer-saber) definida pelo lexema nulidade, geralmente situada no nível das instancias burocráticas.

Por outro lado, como dissemos acima, o discurso pedagógico se caracteriza por uma submodalização de modalidades complexas: poder-fazer-saber $\rightarrow$ podersaber-fazer $\rightarrow$ poder-querer-fazer $\rightarrow$ poder-dever-fazer $\rightarrow$ poder-fazer-crer; querer/dever/poder/fazer, na medida em que se propõe transmitir um saber, criar competência, despertar vocações, gerar a consciência profissional e consolidar vocações que conduzem a uma ação profissional, politica e social dos cidadãos.

Dessa maneira, os discursos científicos, tecnológicos e pedagógicos são aqueles que justificam a existência da universidade - com os recursos económicos necessários para o seu funcionamento - pelo menos que seguem a escrita da lei e dos regulamentos; eles dizem respeito às atividades definidas como os fins a que a Universidade se propõe atingir; ao contrário, o discurso burocrático administrativo concerne às atividades que constituem os meios necessários à obtenção desses fins. Nessas condições, os discursos científico, tecnológico e pedagógico se definem pelas estruturas de poder ligadas à persuasão, enquanto que o discurso burocrático se caracteriza pela modalidade complexa do poderfazer-fazer, isto é, da manipulação.

Nesses termos, uma política científica e tecnológica perversa como aquela do desenvolvimento dependente traz consequências, não apenas as citadas anteriormente, como também, no interior da universidade, das instituições de ensino e pesquisa e outras consequências nefastas, como, por exemplo, a cisão das 
instituições, de modo que seus segmentos ou setores funcionem como repartições estanques, um declínio, qualitativo e quantitativo da produtividade dos discursos, ligadas as atividades próprias da universidade ( os discursos científicos, tecnológicos e pedagógicos). Esses últimos tornam-se, ainda, atividades-pretexto, enquanto que o discurso burocrático se transforma na atividade mais importante, por ela própria, legitimada. Daí resulta toda espécie de conflito e de frustração,

Constatam-se, assim, contradições intoleráveis que se estabelecem entre a sociedade e o Estado, entre sociedade e a Universidade e, no interior das instituições de ensino e pesquisa, entre discursos e práticas incompatíveis. No que concerne aos professores, pesquisadores e estudantes, a sociedade se comporta, alternativamente, como Destinador manipulador e Destinador julgador. Na primeira dessas funções, ela se faz compreender através da Constituição nacional, a legislação relativa à ciência, à tecnologia, à educação, através da publicidade e de outros meios, ela discrimina as aspirações (no modo do querer) e as expectativas (no modo do crer); quanto à ascensão social e à realização profissional; o Estado, seus organismo de financiamento da pesquisa, a própria Universidade fazem o papel de um Adjuvante ou mais ainda, de um Destinador manipulador delegado. A sociedade e as instituições destinam, de certa maneira, ao Destinatário sujeito acadêmico - estudante em diferentes níveis; professor/pesquisador, sobretudo no início da carreira - uma competência modal definida, tanto pelo querer-fazer, dever-fazer, querer-ser e dever-ser, como pelo crer-poder-ser, crer-poder-fazersaber, crer-poder-saber-fazer, no interior de um discurso manipulador sedutor. Este discurso gera, portanto, como acabamos de dizer, aspirações (na ordem do querer) e expectativas (na ordem do crer).

Todavia, a política científica e tecnológica em vigor e suas consequências, fragmentação da Universidade em blocos-estaques, os obstáculos postos à afirmação das identidades científicas e a cooperação entre domínios, a discriminação da pesquisa fundamental, as relações precárias entre a Universidade e a sociedade e, sobretudo, a onipresença do discurso burocrático e administrativo tendem a transformar as Universidades e as outras instituições de ensino e de pesquisa em Antidestinador manipulador. As aspirações e expectativas dos estudantes, dos professores, dos pesquisadores são frustradas. 0 Destinador sujeito do discurso institucional sofre uma transformação na sua competência modal: 
crer-não-poder-fazer-saber, crer-não-poder-saber-fazer, crer-não-poder-ser, crernão-poder-fazer (no nível das expectativas), não-querer ser, não-querer-fazer (no nível das aspirações), não-dever-fazer (no nível da consciência profissional). Assim, ai reencontramos o desencanto, o ceticismo, a negligência.

Contudo, neste segundo momento, a sociedade, que mantém a instituição, o Estado, que impôs a política científica e perversa, intervêm, cada um a seu modo, como Destinador julgador, que determina as sanções: a falta do reconhecimento social, os salários muitos baixos, o mercado de trabalho insuficiente e intolerante, etc. A própria universidade, assim como os organismos encarregados de financiar a pesquisa assumem o papel de Destinador julgador delegado. Este papel se manifesta, então, através dos exames e dos concursos, na avaliação dos projetos de pesquisa e das relações de pesquisa. O Destinatário Sujeito Acadêmico, seus títulos, as posições conquistadas são desqualificados. São enquadrados, nos termos da teoria inoperante, da prática irresponsável, da nulidade.

Tal instituição universitária, na medida em que sustenta o discurso do ensino e da pesquisa, no modo do parecer e o discurso burocrático e administrativo, no modo do ser, reitera seu papel de antidestinador manipulador/julgador. Ela pune, assim, o sujeito do discurso do ensino e da pesquisa, no modo do ser, e recompensa (sanciona positivamente) com prestígio e poder burocrático o Antissujeito Acadêmico que ela gerou. Enfim, a sociedade, enquanto Destinador Julgador último sanciona, negativamente, a Instituição, destinando-lhe a não-credibilidade.

Trata-se, certamente, de questões fortemente complexas, mas acreditamos que uma análise semiótica dessas relações - mas precisamente orientada em direção à Sociossemiótica e à Semiótica da Cultura - assim como uma análise léxico-semântica dos metatermos concernentes podem ser muito úteis para permitir-nos chegar a uma melhor compreensão dos processos em causa.

\section{BIBLIOGRAFIA SUMÁRIA:}

PAIS, Cidmar Teodoro. Conditions sémantico-syntaxiques et sémiotiques de la productivité systémique, lexicale et discursive. Thèse de Doctorat d'État ès-Lettres et Sciences Humaines. Paris: Université de Paris-Sorbonne/Lille: A.N.R.T,, 1993. 
Contribution à une analyse socio-sémiotique du processus culturel: lexique, métatermes, modalités. Acta semiotica et linguistica.. São Paulo, Plêiade, v, 6, p. 101-132, 1996.

. "Sociossemiótica, semiótica da cultura e processo histórico: liberdade, civilização e desenvolvimento". In Anais do V Encontro Nacional da Anpoll. Porto Alegre: Anpoll, 452-461, 1991.

"Análise sociossemiótica de alguns conceitos e valores do processo sociocultural brasileiro contemporâneo". In Estudos Lingüísticos XXIV. Anais de Seminários do GEL. São Paulo: GEL, p. 234-243, 1995a.

"Da semântica cognitiva à semiótica das culturas". In Anais do IX Encontro Nacional da ANPOLL. João Pessoa: ANPOLL, p. 1325-1336, 1995b.

"Identité et tolérance culturelles dans le cadre de la mondialisation: une approche socio-sémiotique”. In Acta semiotica et linguistica, São Paulo, Plêiade, v. 7, p. 169-184, 1998a.

"Conceptualisation, dénomination, désignation, référence. Réflexions à propos de l'énonciation et du savoir sur le monde". In Hommage à Simone Saillard. Textures. Cahiers du Centre dÉtudes Méditerranéennes et Ibéro- Américaines. Lyon: Université Lumière Lyon 2, p. 371-384, 1998b

"Étude comparée de microsystèmes de valeurs des cultures française et brésilienne: essai en sémiotique des cultures". In INFO-CREA - Revue du Centre de Recherches et d'Études Anthropologiques. Lyon, v. 6. p. 13-21, 1999.

"Ciência, tecnologia, educação institucional face a questões suscitadas pela globalização e pela diversidade cultural”. In Revista Brasileira de Lingüística. São Paulo: Terceira Margem/Plêiade, v. 1, n.ํㅜ 1, p. 185-197, 2001.

"Conceptualização, interdiscursividade, arquitexto, arquidiscurso". In Revista Philologus. Rio de Janeiro: CIFEFIL, ano 8, n. 23, p. 101-1, 2002.

"Estigma, preconceito, discriminação: percalços da cidadania". In A Teia do Saber - Um novo olhar sobre a formação do professor. 1 ed. Mogi das Cruzes - SP: Oriom Editora, 2004, v.1, p. 93-106.

"Semiótica da educação, propaganda e publicidade: confrontos e impactos". In Estudos Lingüísticos. v. XXXIV, p.1266 - 1271, 2005a.

"Propaganda e publicidade no interdiscurso: os sujeitos dos discursos científico e tecnológico em busca de seus objetos de valor". In Revista philologus. v.1, p.17 - 132, 2005b. 